\title{
Evaluation of in vitro and in vivo anthelmintic efficacy of Cyperus compressus Linn., a traditionally used anthelmintic plant in parasite-animal models
}

\author{
Amar Deep Soren ${ }^{1 *}$ and Arun Kumar Yadav ${ }^{2}$
}

\begin{abstract}
Background: The decoction of the roots of Cyperus compressus (Cyperaceae) is used to treat helminth infection by the Santhal tribe of Assam. The study evaluated the anthelmintic efficacy claims of the plant $\mathrm{C}$. compressus through pre-clinical in vitro and in vivo studies employing available parasite-animal models such as Hymenolepis diminutaWistar rat (cestode) and Syphacia obvelata-Swiss mice (nematode) models.

Results: Phytochemical analysis revealed the presence of alkaloids, glycosides, reducing sugars, flavonoids, terpenoids, tannins, and steroids. In vitro studies were conducted employing $\mathrm{H}$. diminuta and S. obvelata. In vitro studies against $H$. diminuta revealed mortality of parasites at $8.3 \pm 0.05 \mathrm{~h}$ at the highest concentration of $C$. compressus methanolic root extract $(30 \mathrm{mg} / \mathrm{ml})$, whereas reference drug praziquantel (PZQ), showed mortality at $5.84 \pm 0.01 \mathrm{~h}$. Against S. obvelata, in the same concentration of the extract, mortality of parasites occurred in a much later time of $24.13 \pm 0.03 \mathrm{~h}$, whereas in the reference drug albendazole (ABZ), the parasites showed mortality at $7.24 \pm 0.08 \mathrm{~h}$. In vivo studies against $\mathrm{H}$. diminuta revealed $61.74 \%$ reduction in the eggs per gram (EPG) counts and $24 \%$ reduction in worm counts at the highest dose of $700 \mathrm{mg} / \mathrm{kg}$ body weight (b.w.) of plant extract. Against S. obvelata, at $700 \mathrm{mg} / \mathrm{kg}$ b.w., $28.92 \%$ and $33.85 \%$ reduction in EPG and worm counts were recorded respectively.

Conclusion: Although the reference drugs showed better in vitro and in vivo efficacy, the plant extract showed a better in vitro efficacy against cestode parasite compared to its nematode counterpart indicating that it possesses a better cestocidal efficacy. EPG reductions were higher against $\mathrm{H}$. diminuta, whereas worm count reduction was higher against $S$. obvelata. The findings justify the use of C. compressus as an anthelmintic in the traditional medicine of the Santhals of India.
\end{abstract}

Keywords: Cyperus compressus, Hymenolepis diminuta, In vitro, In vivo, Syphacia obvelata

\section{Background}

Helminth parasite infections are the most common type of infections in tropical and sub-tropical regions and affect the poor and deprived communities [1]. It is estimated that approximately 1.5 billion people ( $24 \%$ of the world's population) are infected with soil-transmitted helminthic infections worldwide [2]. India contributes about $25 \%$ to the total global cases of helminth infections with 220.6

\footnotetext{
*Correspondence: amar4deep@gmail.com

${ }^{1}$ Department of Zoology, B. Borooah College, Guwahati, Assam 781007, India Full list of author information is available at the end of the article
}

million children needing preventive chemotherapy [3]. Traditional medicines have been used to treat helminthiasis globally [4]. It is the oldest and the most widely used system of medicine which relies on past experiences and observations passed from the ancestors to their children [5]. Although the usage of traditional medicine has increased worldwide, research in this area is inadequate [6]. Several authors have scientifically validated the efficacy of plants used in traditional medicines to treat helminthiasis through both in vitro and in vivo studies and have found them to be efficacious $[7,8]$. 
C. compressus (Cyperaceae) is a weed widely abundant in open fields. It is found in tropical Africa, Asia, and the USA [9]. In India, it is found in the states of Assam, Kerala, and Punjab [10]. It is commonly called as Mutha by the Santhal tribe in Assam, India, who have been using the roots decoction to treat helminthiasis [11]. In addition, the plant is also used to treat cuts and wounds [12]. Studies reporting the anthelmintic efficacy of $C$. compressus are lacking. Most authors have restricted their study to in vitro efficacy studies of traditionally used medicinal plants alone [13-15]. The in vivo efficacy studies on such traditionally used medicinal plants are scanty. Such plants should be evaluated for efficacy through both in vitro and in vivo tests in order to be accepted into scientific medicine [16]. With these as background, this study aimed to validate the claims of anthelmintic efficacy of $C$. compressus using in vitro and in vivo studies by employing suitable parasite-animal models.

\section{Methods}

\section{Plant material}

Fresh roots of C. compressus were collected from fields in Kokrajhar, Assam, India. They were brought to the laboratory, washed with tap water, shade dried, powdered, and extracted with methanol. Herbarium of plant material was made and identified by a plant taxonomist from the Department of Botany in the same institute. It was identified by comparing with existing specimen and an accession number was assigned. The herbarium specimen has been deposited in the herbarium museum of the Department of Botany and a copy of the herbarium specimen has also been retained in the laboratory.

\section{Experimental animals}

Swiss albino mice of either sex (25-30 g) were used for in vivo studies against Syphacia obvelata and Wistar rats of either sex (150-190 g) of about 7 to 8 weeks were used for in vivo studies against Hymenolepis diminuta. All the animals used were procured from the laboratory of the Department of Zoology. They were inbred and maintained in separate cages in adequate laboratory conditions at 22 ${ }^{\circ} \mathrm{C} \pm 3{ }^{\circ} \mathrm{C}$. They had ad libitum access to food and water and cages were cleaned once daily. Adequate lighting to maintain $12 \mathrm{~h}$ day and $12 \mathrm{~h}$ night cycle was provided [17]. Approval and permission to use the animals was obtained from the Institutional Ethics Committee (IEC) (animal models). All experiments on laboratory animals were performed strictly according to the IEC and ARRIVE (Animal Research: Reporting of In Vivo Experiments) guidelines.

\section{Phytochemical analysis}

The plant material was subjected to various qualitative tests to detect the presence of phytochemicals using standard protocols as described by Trease and Evans [18] and Sofowora [19].

\section{In vitro anthelmintic study}

Test parasites were collected from freshly necropsied rodents. Parasites $(n=5)$ were placed in three different concentrations of the extract, namely 10,20 , and $30 \mathrm{mg} /$ $\mathrm{ml}$ in triplicates. Another set of parasites were placed in reference drug praziquantel (PZQ, $1 \mathrm{mg} / \mathrm{ml}$ ) in case of $H$. diminuta and albendazole (ABZ, $5 \mathrm{mg} / \mathrm{ml}$ ) in case of $S$. obvelata to compare the efficacy and a final set of worms were placed in phosphate-buffered saline (PBS) which served as control. Parasites were monitored for paralysis and mortality at regular intervals and the time taken for these events to occur were recorded and compared with that of the reference drug [4].

\section{In vivo anthelmintic study}

Adult Wistar rats pre-infected with cysticercoids $(n=5)$ were used for the in vivo study. Infection was maintained in the laboratory by feeding the intermediate host, Tribolium confusum with gravid segments. Prior to inoculation, $T$. confusum were starved for $48 \mathrm{~h}$ and restored to their diet after $72 \mathrm{~h}$. After 28 days, they were dissected to retrieve the cysticercoids which were then inoculated to the rats. Establishment of infection was confirmed by the presence of gravid segments in the fecal matter after 18-20 days [4]. Against S. obvelata, infection was maintained in laboratory Swiss albino mice, by placing fecal matter containing eggs in the cages of uninfected mice. After ingestion, adults develop after a period of 18-20 days [8]. Animals in which parasite infection was established were used to carry out the study.

Animals were administered three different doses of the plant extract. Three doses were selected on the basis of the dose administered by traditional practitioners to their clients to compare the effects [8]. Accordingly, the prescribed dose of $350 \mathrm{mg} / \mathrm{kg}$ b.w. was taken as the median dose and two other doses, one exponentially lower (175 mg/kg b.w.) and one higher were selected (700 mg/ $\mathrm{kg}$ b.w.) to compare the effects. One group of animals received reference drug, PZQ (5 $\mathrm{mg} / \mathrm{kg}$ b.w.) in case of cestodes and ABZ (20 mg/kg b.w.) in case of nematodes, whereas the final group received only the vehicle (phosphate-buffered saline) and served as negative control. Each of the 5 groups comprised of 5 infected animals ( $n$ $=5$ ) and a total of 25 animals were used for each in vivo study. Animals were dosed once daily in the morning for 5 days [17] and prior to sacrifice, they were euthanized using chloroform. After the study, the remains of the deceased animals were burnt in an incinerator. Animals were maintained and handled as per Organization for Economic Co-operation and Development (OECD) guidelines [17] and IEC. 


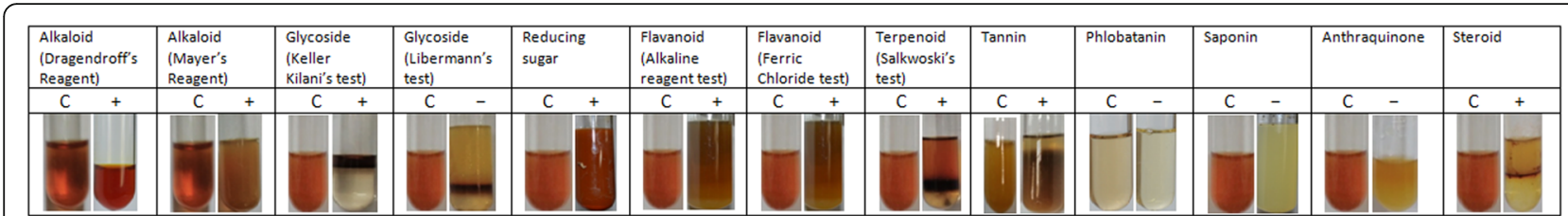

Fig. 1 Phytochemical analysis of $C$. compressus root. C, control; +, presence; -, absence

\section{Statistical analysis}

Data obtained from the experiments were processed using OriginPro 8. All the experimental data are represented as mean \pm standard error of mean (SEM). In vitro tests data were analyzed by Students' $t$ test and data from in vivo anthelmintic tests were analyzed by one-way analysis of variance (ANOVA) followed by Tukey's post hoc test for multiple comparisons. $p$ value $\leq 0.05$ was considered to be statistically significant.

\section{Results}

\section{Phytochemical analysis}

Phytochemical analysis revealed the presence of alkaloids, glycosides, reducing sugars, flavonoids, terpenoids, tannins, and steroids. Others such as saponins, phlobatannins, and anthraquinones were found to be absent (Fig. 1).

\section{In vitro anthelmintic study}

Exposure to $C$. compressus methanolic root extract at 10, 20, and $30 \mathrm{mg} / \mathrm{ml}$ concentration showed a concentrationdependent efficacy against all the test parasites. Against $H$. diminuta, at the highest concentration $(30 \mathrm{mg} / \mathrm{ml})$, the parasites showed mortality at $8.3 \pm 0.05 \mathrm{~h}$, whereas in reference drug PZQ, the parasites showed mortality at $5.84 \pm 0.01 \mathrm{~h}$. Control worms survived up to $40.36 \pm 0.14 \mathrm{~h}$ (Fig. 2). Against $S$. obvelata, the parasites showed mortality at $24.13 \pm 0.03$, $7.24 \pm 0.08$, and $33.07 \pm 0.05 \mathrm{~h}$ at the highest concentration (30 mg/ml), reference drug ABZ and control respectively (Fig. 3).

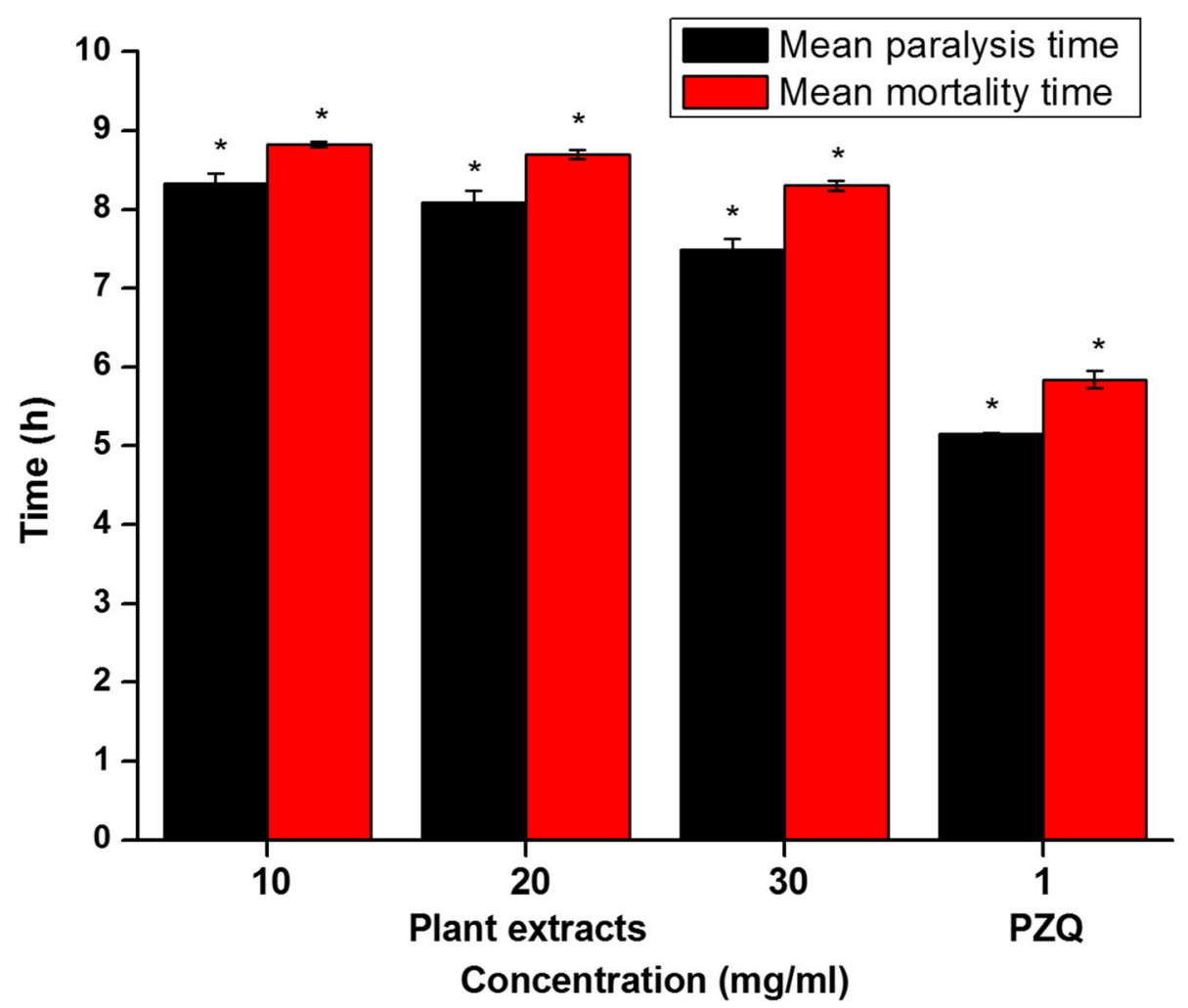

Fig. 2 In vitro anthelmintic efficacy of $C$. compressus methanolic root extract against $H$. diminuta. Data is expressed as mean $\pm S E M$. ${ }^{*} p<0.0001$ compared with control group, Students' $t$ test 


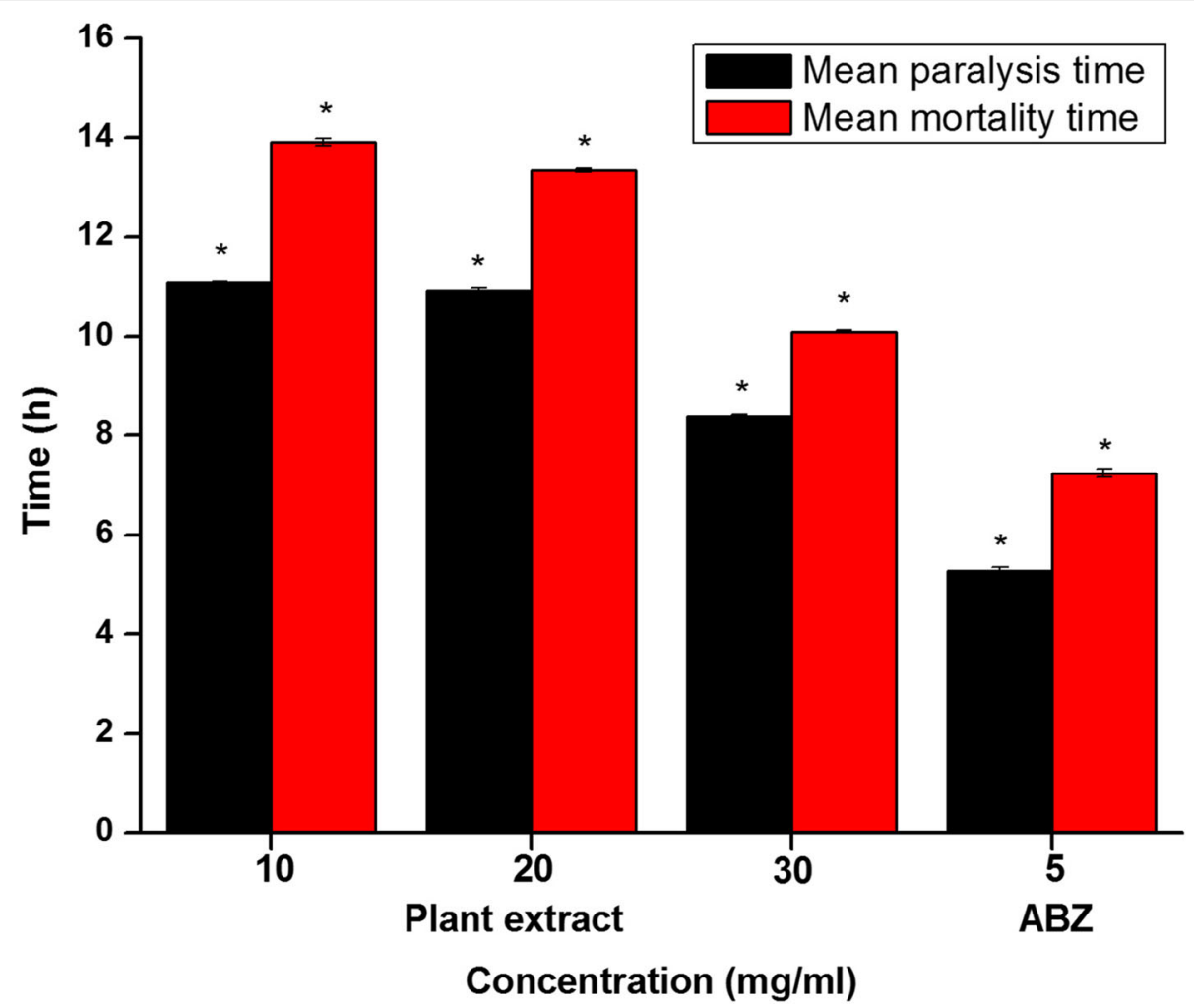

Fig. 3 In vitro anthelmintic efficacy of C. compressus methanolic root extract against S. obvelata. Data is expressed as mean \pm SEM. ${ }^{*} p<0.0001$ compared with control group, Students' $t$ test

\section{In vivo anthelmintic study}

\section{Effects on cestode, $\boldsymbol{H}$. diminuta}

Administration of $C$. compressus root extract to the rats infected with $H$. diminuta worms showed a significant reduction $(p<0.001)$ in egg per gram of faeces (EPG) counts and worm recovery rate in a dose-dependent manner (Table 1). Animals treated with $700 \mathrm{mg} / \mathrm{kg}$ dose of the extract for 5 days (days 21-25 post-inoculation of cysticercoids) showed $61.74 \%$ reduction in the EPG counts compared to the EPG counts of pre-treatment period (days 18 $-20)$. The reduction in worm count was found to be 24\%. Animals treated with reference drug PZQ (5 $\mathrm{mg} / \mathrm{kg}$ b.w.) showed $86.10 \%$ and $88 \%$ reduction in EPG and worm counts, respectively. The control animals showed $1.13 \%$ increase in EPG and no change in worm counts.

Table 1 In vivo anthelmintic effect of C. compressus methanolic root extract* on adult stages of $H$. diminuta infection in rats

\begin{tabular}{|c|c|c|c|c|c|}
\hline \multirow{2}{*}{$\begin{array}{l}\text { Treatment } \\
\text { groups } \\
(\mathrm{mg} / \mathrm{kg})\end{array}$} & \multicolumn{2}{|l|}{ EPG (mean \pm SEM) } & \multirow{2}{*}{$\begin{array}{l}\text { Percentage } \\
\text { difference } \\
\text { in EPG (A-B) }\end{array}$} & \multirow{2}{*}{$\begin{array}{l}\text { Worm count } \\
\text { at necropsy } \\
\text { (mean } \pm \text { SEM) }\end{array}$} & \multirow{2}{*}{$\begin{array}{l}\text { Percentage } \\
\text { reduction } \\
\text { in worm } \\
\text { count }(\%)\end{array}$} \\
\hline & Pre-treatment $18-20$ days $(\mathrm{A})$ & Post-treatment 26-28 days (B) & & & \\
\hline Control & $21676 \pm 195.22$ & $21923 \pm 26.07$ & 1.13 & $5.0 \pm 0.00$ & 0 \\
\hline \multicolumn{6}{|l|}{ Plant extract } \\
\hline 175 & $21652 \pm 105.29$ & $14303 \pm 110.51^{\mathrm{ab}}$ & -33.94 & $4.4 \pm 0.24$ & 12 \\
\hline 350 & $22663 \pm 119.43$ & $12561 \pm 122.27^{\mathrm{ab}}$ & -44.57 & $4.2 \pm 0.37$ & 16 \\
\hline 700 & $22583 \pm 102.33$ & $8368 \pm 192.61^{\mathrm{ab}}$ & -61.74 & $3.8 \pm 0.20$ & 24 \\
\hline \multicolumn{6}{|l|}{ Praziquantel } \\
\hline 5 & $22000 \pm 221.14$ & $3057 \pm 48.26^{\mathrm{ab}}$ & -86.10 & $0.6 \pm 0.24^{\mathrm{a}}$ & 88 \\
\hline
\end{tabular}

*Administration of plant extract and praziquantel on days 21-25 post-inoculation with five cysticercoids/rat $(n=5)$

${ }^{a} p<0.001$ as compared to control value

${ }^{\mathrm{b}} p<0.001$ as compared to pre-treatment, one-way ANOVA, followed by Tukey's test 
Table 2 In vivo anthelmintic effect of C. compressus methanolic root extract* on S. obvelata in mice

\begin{tabular}{|c|c|c|c|c|c|c|}
\hline \multirow{2}{*}{$\begin{array}{l}\text { Treatment } \\
\text { groups } \\
(\mathrm{mg} / \mathrm{kg})\end{array}$} & \multicolumn{2}{|l|}{ EPG (mean \pm SEM) } & \multirow{2}{*}{$\begin{array}{l}\text { Percentage } \\
\text { difference } \\
\text { in EPG }\end{array}$} & \multicolumn{2}{|c|}{ Worm count at necropsy } & \multirow{2}{*}{$\begin{array}{l}\text { Percentage } \\
\text { reduction } \\
\text { in worm } \\
\text { count (\%) }\end{array}$} \\
\hline & Pre-treatment (days 1-3) & Post-treatment (days 9-11) & & Min-Max & Mean \pm SEM & \\
\hline Control & $28.4 \pm 0.87$ & $29.8 \pm 0.37$ & 4.9 & $62-114$ & $90.2 \pm 9.07$ & 0 \\
\hline \multicolumn{7}{|l|}{ Plant extract } \\
\hline 175 & $26 \pm 1.58$ & $22 \pm 4.19$ & -15.38 & $42-98$ & $68.2 \pm 10.35$ & 24.39 \\
\hline 350 & $25 \pm 1.94$ & $20.4 \pm 3.14$ & -18.4 & $41-92$ & $65.4 \pm 10.94$ & 27.49 \\
\hline 700 & $24.2 \pm 1.59$ & $17.2 \pm 2.98$ & -26.61 & $40-86$ & $59 \pm 7.93$ & 33.85 \\
\hline \multicolumn{7}{|l|}{ Albendazole } \\
\hline 20 & $26.4 \pm 0.50$ & $4.8 \pm 0.37^{\mathrm{ab}}$ & -75.75 & $4-10$ & $8 \pm 0.70^{a}$ & 91.13 \\
\hline
\end{tabular}

*Administration of plant extract and albendazole on days 4-8 after pre-treatment EPG $(n=5)$

${ }^{a} p<0.001$ as compared to control value

${ }^{\mathrm{b}} p<0.001$ as compared to pre-treatment, one-way ANOVA, followed by Tukey's test

\section{Effects on nematode, S. obvelata}

Administration of C. compressus root extract to mice infected with S. obvelata worms showed a decrease in EPG counts of the treated animals during the post-treatment period (Table 2). During the first 3 days (pre-treatment EPG), eggs were detected in the cellophane test of all animals. However, after 5 days of treatment, $28.92 \%$ and $33.85 \%$ reduction in EPG and worm counts respectively were recorded for the highest dose. The ABZ-treated animals $(20 \mathrm{mg} / \mathrm{kg}$ b.w.) showed $75.75 \%$ and $91.13 \%$ reduction in EPG and worm counts respectively. The control animals showed $4.9 \%$ increase in EPG post-treatment.

\section{Discussion}

Although, several medicinal plants continue to be used in traditional medicine, scientific data to back up their efficacy claims are lacking [5]. Plants continue to be used as components in traditional medicine and other forms of medicine [20]. A large part of the world still relies on traditional medicine to treat various ailments. Phytochemicals found in plants are responsible for their various effects [5]. The present study revealed the presence of alkaloids, glycosides, reducing sugars, flavonoids, terpenoids, tannins, and steroids. Earlier, Rameshkumar et al. (2011) reported the presence of about 22 volatile compounds from the oil obtained from the roots of $C$. compressus [21]. Also, a study by Datta et al. (2018) revealed that $C$. compressus is a rich source of phenolics, flavonoids, and water-soluble vitamins [22]. A similar study was reported by Davuluri et al. (2020), where phytochemical screening of plant extracts revealed the presence of alkaloids, flavonoids, tannins, saponins, and amino acids. Also, the plant extract showed a dosedependent anthelmintic efficacy and the authors attributed its efficacy to these phytochemicals [13]. The in vitro studies in the present experiment showed significant efficacy of the extract against $H$. diminuta. The plant extract showed a dose-dependent activity against both the test parasites. The presence of these phytochemicals may be attributed to the observed anthelmintic efficacy of $C$. compressus.

Efficacy of a plant is confirmed when in vitro studies are supplemented by in vivo studies [8]. Hence, the undertaken study has incorporated both the in vitro as well as in vivo studies. The in vivo studies revealed significant efficacy of the extract against both $H$. diminuta and $S$. obvelata. Furthermore, better efficacy was observed against $H$. diminuta in terms of EPG reduction which showed $61.74 \%$, whereas reduction in worm counts was better against $S$. obvelata which showed $33.85 \%$ reduction in worm counts. A similar study by Gogoi and Yadav (2016) on Caesalpinia bonducella revealed that the extract showed a better efficacy against $S$. obvelata, where the highest dose $(800 \mathrm{mg} / \mathrm{kg})$ caused $93 \%$ reduction of worm load, and $85 \%$ worm load reduction against $H$. diminuta [8].

\section{Conclusion}

Efficacy claims of any medicinal plant should undergo scientific validations supplemented by both in vitro as well as in vivo assays in suitable animal models. The study reported significant in vitro as well as in vivo efficacy of $C$. compressus against $H$. diminuta and $S$. obvelata which validates its use as an anthelmintic in the traditional medicine system of the Santhal tribe in Assam, India. The results further warrant the isolation of active component responsible for its efficacy.

\section{Abbreviations}

ABZ: Albendazole; ANOVA: Analysis of variance; b.w.: Body weight; EPG: Eggs per gram; IEC: Institutional ethics committee; OECD: Organization for Economic Co-operation and Development; PZQ: Praziquantel; SEM: Standard error of mean

\section{Acknowledgements}

The authors thank Larisha Lyndem, Associate Professor, Department of Zoology, Visva Bharati University, for allowing to carry out in vivo studies in the Parasitology lab. A fellowship awarded to ADS from the UGC, New Delhi, is duly acknowledged. 


\section{Plant authentication}

Plant material was identified by a plant taxonomist from the Department of Botany, NEHU, Shillong. Plant material was assigned accession number (NEHU-12085) and a copy has been submitted in the herbarium museum of the Department of Botany, NEHU. Research involving plant was approved by the Research Committee of NEHU.

\section{Authors' contributions}

ADS executed the experiments, analysed the data, and wrote the first draft. AKY conceptualised and supervised the study and edited and finalised the draft. All authors read and approved the final manuscript.

\section{Funding}

The study did not receive any funding from agencies in the public, commercial, or not-for-profit sectors.

\section{Availability of data and materials}

Data and materials are available upon request.

\section{Ethics approval and consent to participate}

Animals used were procured from the laboratory animal room of NEHU. All experiments on animals were approved by the Institutional Ethics Committee (Animal models), NEHU, Shillong, and written consent was obtained (Vide, Member Secretary, IEC, NEHU, dated 4 December 2014, approval number 01). Also, the animal experiments complied with the ARRIVE guidelines.

\section{Consent for publication}

Not applicable

\section{Competing interests}

The authors declare that they have no competing interests.

\section{Author details}

${ }^{1}$ Department of Zoology, B. Borooah College, Guwahati, Assam 781007, India. ${ }^{2}$ Department of Zoology, North-Eastern Hill University, Shillong, Meghalaya 793022, India.

Received: 29 July 2020 Accepted: 29 November 2020

Published online: 04 December 2020

\section{References}

1. Mitra AK, Mawson AR (2017) Neglected tropical diseases: epidemiology and global burden. Trop Med Infect Dis 2(3):36. https://doi.org/https://doi.org/10. 3390/tropicalmed2030036

2. WHO (2020) Fact sheets. Soil-transmitted helminth infections. https://www who.int/news-room/fact-sheets/detail/soil-transmitted-helminth-infections. Accessed 16 April 2020

3. Salam N, Azam S (2017) Prevalence and distribution of soil-transmitted helminth infections in India. BMC Public Health 17(1):201. https://doi.org/ https://doi.org/10.1186/s12889-017-4113-2

4. Deori K, Yadav AK (2016) Anthelmintic effects of Oroxylum indicum stem bark extract on juvenile and adult stages of Hymenolepis diminuta (Cestoda), an in vitro and in vivo study. Parasitol Res 115(3):1275-1285. https://doi.org/ https://doi.org/10.1007/s00436-015-4864-6

5. Ozioma EOJ, Chinwe OAN (2019) Herbal medicine. In: Builders P (ed) Herbal medicines in African traditional medicine. IntechOpen. http://dx.doi.org/ https://doi.org/10.5772/intechopen.80348

6. Chanda S, Parekh J, Vaghasiya Y, Dave R, Baravalia Y, Nair R (2015) Medicinal plants - from traditional use to toxicity assessment: a review. Int J Pharm Sci Res 6(7):2652-2670. https://doi.org/https://doi.org/10.13040/IJPSR.0975-8232. 6(7).2652-70

7. Gogoi S, Yadav AK (2017) Therapecutic efficacy of the leaf extract of Croton joufra Roxb. Against experimental cestodiasis in rats. J Parasit Dis 41(2):417422. https://doi.org/https://doi.org/10.1007/s12639-016-0819-9

8. Gogoi S, Yadav AK (2016) In vitro and in vivo anthelmintic effects of Caesalpinia bonducella (L.) Roxb. Leaf extract on Hymenolepis diminuta (Cestoda) and Syphacia obvelata (Nematoda). J Intercult Ethnopharmacol 5(4):427-433. https://doi.org/https://doi.org/10.5455/jice.20160821024821

9. Bhandari MM (1978) Flora of Indian Desert. Jodhpur, India, Scientific Publishers
10. India Biodiversity Portal (2020) Cyperus compressus. L. https:// indiabiodiversity.org/species/show/229407. Accessed 23 July 2020.

11. Soren AD, Yadav AK, Dhar ED (2019) Toxological evaluation of Cyperus compressus Linn. A traditionally used anthelmintic plant in India. Orient Pharm Exp Med 2019:1-6. https://doi.org/https://doi.org/10.1007/s13596019-00413-w

12. Dangol DR, Gurung SB (1991) Ethnobotany of the Tharu tribe of Chitwan district, Nepal. Int J Pharmacogn 29(3):203-209. https://doi.org/https://doi. org/10.3109/13880209109082879

13. Davuluri T, Chennuru S, Pathipati M, Krovvidi S, Rao GS (2020) In vitro anthelmintic activity of three tropical plant extracts on Haemonchus contortus. Acta Parasitol 65(1):11-18. https://doi.org/https://doi.org/10.2478/ s11686-019-00116-x

14. Ishnava KB, Konar PS (2020) In vitro anthelmintic activity and phytochemical characterization of Corallocarpus epigaeus (Rottler) Hook. f. tuber from ethyl acetate extracts. Bull Natl res cent 44:33. https://doi.org/https://doi.org/10. 1186/s42269-020-00286-z

15. Yongwa G, Ngnoda BFNF, Ndjonka D, Saotoing P (2020) In vitro anthelmintic activity of aqueous and ethanolic extract of Senna italica (Caesalpiniaceae) on three-stages of Haemonchus contortus. J Pharm Res Int 32(3):25-34. https://doi.org/https://doi.org/10.9734/jpri/2020/v32i330411

16. Rates SMK (2001) Plants as source of drugs. Toxicon 39:603-613. https://doi. org/https://doi.org/10.1016/S0041-0101(00)00154-9

17. OECD 407 (2008) OECD guidelines for testing of chemicals. Organization for Economic Co-operation and Development, Paris, France

18. Trease GE, Evans WC (2002) Pharmacognosy, 15th edn. Saunders Publishers, London

19. Sofowora A (1993) Screening plants for bioactive agents, Medicinal plants and traditional medicine in Africa, 2nd edn. Spectrum Books Limited, Sunshine House, Ibadan, Nigeria

20. Girach RD, Khan H, Ahmad M (2003) Botanical identification of Thuhar, seldom used as Unani medicine. Hamdard Med XLVI (1):27-33

21. Rameshkumar KB, Sudheesh N, George V, Mohanan N (2011) Volatile constituents of the roots of Cyperus compressus Linn. J Essent Oil Res 23(3): 39-41. https://doi.org/https://doi.org/10.1080/10412905.2011.9700455

22. Datta S, Seal T, Sinha BK, Bhattacharjee S (2018) RP-HPLC based evidences of rich sources of phenolics and water-soluble vitamins in an annual sedge Cyperus compressus. J Phytopharmacol 7(3):305-311

\section{Publisher's Note}

Springer Nature remains neutral with regard to jurisdictional claims in published maps and institutional affiliations.

\section{Submit your manuscript to a SpringerOpen ${ }^{\circ}$ journal and benefit from:}

- Convenient online submission

- Rigorous peer review

- Open access: articles freely available online

High visibility within the field

- Retaining the copyright to your article

Submit your next manuscript at $\boldsymbol{\nabla}$ springeropen.com 